\title{
B-learning, Recursos Educativos Digitais e Ensino Profissional: Uma estratégia de apoio ao desenvolvimento da Prova de Aptidão Profissional
}

\author{
António Fernandes Gonçalves ${ }^{1}$, Guilhermina Lobato Miranda ${ }^{2}$, Nuno Barrela ${ }^{3}$ \\ afgoncalves61@gmail.com, gmiranda@ie.ulisboa.pt, nbarrela@gmail.com \\ ${ }^{1}$ Escola Profissional da Serra da Estrela, Av. Dos Hermínios, 10, 6270-480, Seia, Portugal \\ ${ }^{2}$ Instituto de Educação, Universidade de Lisboa, Alameda da Universidade, 1649-013, Lisboa, Portugal \\ ${ }^{3}$ Profissional independente em multimédia, Pr. João Azevedo Coutinho, 7, 1170-19o, Lisboa, Portugal
}

DOI: 10.17013/risti.20.131-146

\begin{abstract}
Resumo: A realização da Prova de Aptidão Profissional (PAP) dos cursos profissionais, em escolas do interior do país, coloca alunos e professores acompanhantes perante algumas dificuldades que podem ser minimizadas com a utilização das tecnologias digitais. No ano letivo de 2013/14, numa turma de uma escola profissional do distrito da Guarda, desenvolveu-se uma experiência que visou criar um sistema de apoio ao acompanhamento e realização das PAP, com duas componentes: A implementação e manutenção do apoio em regime B-learning, através do Google Drive; A produção e disponibilização online, sustentada na Teoria Cognitiva da Aprendizagem Multimédia, de recursos educativos digitais. Os principais resultados, neste caso específico, indicam que é possível facilitar a interação entre o professor acompanhante e os alunos, aumentando a envolvência e a eficácia do acompanhamento, a compreensão da estrutura da PAP, as capacidades de pesquisa online e a competência para a construção de diapositivos eletrónicos.
\end{abstract}

Palavras-chave: B-learning; Ensino profissional; Recursos Educativos Digitais; Prova de Aptidão Profissional.

\section{B-learning, Digital Educational Resources and Vocational Education and Trainning (VET): A strategy to support the development of Professional Skill Examination}

\begin{abstract}
The accomplishment of Vocational Aptitude Test (VAT) of professional courses in schools from the inside of the country, presents to students and accompanying teachers some difficulties that can be minimized with the use of digital technologies. In the academic year 2013/14, in a class of a vocational school in the district of Guarda, an intervention has been developed that aimed to create a support system for the monitoring and implementation of VAT, with two components: implementation and maintenance of the B-learning support system, through Google Drive; production and online availability of digital educational resources sustained in Cognitive Theory of Multimedia Learning. The main
\end{abstract}


results in this particular case, indicate that it is possible to facilitate the interaction between the accompanying teacher and the students, increasing the involvement of students and the effectiveness of monitoring, and enhancing the understanding of the structure of the VAT, online search capabilities and the competence to build electronic devices.

Keywords: B-learning; Digital Educational Resources; Professional Skill Examination; Vocational Education and Trainning.

\section{Introdução}

O ensino profissional tem caraterísticas particulares que o diferenciam de outras modalidades de ensino. O seu Plano Curricular, que se desenvolve em três anos letivos, está estruturado em disciplinas compostas por módulos, tem um período de experiência formativa em contexto de trabalho - Formação em Contexto de Trabalho, e uma prova de aferição das competências profissionais - Prova de Aptidão Profissional (PAP). Esta Prova, que se desenvolve no último ano de formação, visa pôr em evidência as competências adquiridas ao longo do curso e demonstrar a preparação do aluno para entrar no mercado de trabalho. Para esse efeito, os alunos, acompanhados por um ou mais professores, desenvolvem individualmente um trabalho de planeamento e concretização de um projeto, que culmina na apresentação de um relatório defendido em prova pública. Neste processo, que se desenrola maioritariamente fora do horário letivo, alunos e professores acompanhantes encontram-se condicionados nos seus contatos presenciais necessários ao desenvolvimento daquela Prova. A interioridade regional, por sua vez, agrava ainda mais esses constrangimentos, dado que muitos alunos moram em localidades distantes e com transportes públicos limitados nos seus horários, dificultando, deste modo, o acompanhamento e avaliação do processo. Por outro lado, não há, nestes cursos, a lecionação formal de conteúdos que são fundamentais para o desenvolvimento adequado da Prova. O conhecimento das potencialidades, técnicas e regras de pesquisa online, o respeito pelos Direitos de Autor e a utilização correta de software editor de diapositivos eletrónicos, são temas que o aluno que desenvolve a sua PAP, deveria dominar.

A experiência que descrevemos neste artigo, que envolveu catorze alunos e nove professores, desenvolveu-se numa escola profissional da região da Serra da Estrela. Pretendeu minimizar os constrangimentos identificados no acompanhamento e na realização da Prova, substituindo a fraca possibilidade de contato presencial para acompanhamento da PAP, por um regime de B-learning e colmatando a falta formal dos referidos conteúdos através da criação e disponibilização online de um conjunto de Recursos Educativos Digitais.

\section{Enquadramento}

\subsection{Tecnologias de Informação e Comunicação na Educação}

A Escola tem sido, nos três últimos decénios, palco da introdução e experimentação de tecnologias de informação e comunicação (TIC) na prática pedagógica, dado que não é imune aos movimentos e tendências gerais da sociedade em que está inserida. Existe ainda a expectativa de que estas tecnologias podem induzir melhorias no processo de 
ensino e aprendizagem. A Internet tem especial destaque nessas "novas" tecnologias, sendo indiscutível que a sua implementação na Escola tem sido um fator potenciador de mudança (Abreu et al., 2015). Como afirmam Coutinho \& Alves (2010) e Jonassen (2007), as TIC e a Internet não são apenas meios de comunicação e ferramentas neutras, mas antes, ferramentas sociais e cognitivas que vieram alterar a forma de comunicar, interagir e aprender. A possibilidade de ter disponível num repositório grande parte do saber humano, a facilidade de fazer chegar aos outros o que se pensa e cria, a capacidade de comunicar instantaneamente com alguém cuja localização física não é determinante e ainda, o poder contribuir para a criação coletiva do saber, gerou um enorme potencial de criação de ambientes de aprendizagem inovadores e desafiantes (Coutinho \& Alves, 2010). Foram criadas novas possibilidades de contextos de aprendizagem formais e informais, permitindo, inclusivamente, ultrapassar o modelo presencial de ensino, com a existência de modelos total ou parcialmente a distância.

\section{Tipo de ferramenta}

Social networking

Social bookmarking

Escrita colaborativa

Comunicação

Edição

Pesquisa

Plataforma de ensino online

Alojamento e partilha de multimédia

\section{Ferramenta (exemplos)}

Facebook; Twitter; Google +; Ning; LinkdIn; MySpace

Scoop.it; Del.icio.us; Pinterest; Pearltrees; CiteULike

WordPress; Bloguer; MediaWiki; Wikipedia; Wikiversidade; PbWorks; Wikispaces; Google Apps

\section{Skype; Google Hangouts; Messenger}

Wix; Prezi; Picktochart; Flipsnack (Edu); Powtoon; Moovly; ThingLink; Google Apps; FileLab Audio Editor; YouTube Editor; PodOmatic; TalkShoe

Google; Yahoo; Bing

Google Apps; Moodle; Udemy; P2PU; Learnopia; Edmodo

YouTube; Vimeo; Wikimedia Commons; Flickr; Glogster EDU; Internet Archive; MyPodcast.com.

Tabela 1 - Alguns tipos de ferramentas Web 2.o mais usadas em educação.

O manancial de ferramentas disponíveis na Web é extenso e variado, sejam estas de caráter lúdico, comercial, social, editorial, académico e também educativo. Mesmo aquelas cujo objetivo inicial é diverso da educação podem ter aplicação na atividade de ensino e aprendizagem. A utilização destas ferramentas em contexto educativo implica um bom conhecimento das suas funções, potencialidades, limitações e uma constante atualização. Apresentam-se na Tabela 1, baseada em Coutinho \& Alves (2010), alguns exemplos de ferramentas online, Web 2.o, que têm vindo a ser usadas em educação.

\subsection{Ensino a distância e B-learning}

O E-learning tem as vantagens decorrentes do facto de ser um ensino não presencial, designadamente, maior acessibilidade e flexibilidade permitindo, deste modo, 
colocar a enfâse das estratégias de ensino no aluno. Contudo, tem também alguns constrangimentos, como o limitado contato humano e eventuais dificuldades ou falhas técnicas decorrentes da dependência das ferramentas tecnológicas usadas. Existem vários graus de implementação do E-learning, consistindo, no entanto, a sua forma mais simples na criação de um repositório de materiais pedagógicos usados em aulas presenciais que, assim, ficam disponíveis para consulta pelos alunos fora do espaço físico da escola.

O regime misto de ensino-aprendizagem, com articulação das componentes presencial e online, designa-se blended-learning, ou simplesmente, B-learning. Singh \& Reed (2001) definem B-learning como a combinação entre ensino online e ensino offline, acontecendo o primeiro através da Internet ou Intranet e o segundo em sala de aula. No fundo, com o B-learning tenta ter-se o melhor dos dois mundos, como afirmam Coutinho \& Bottentuit (2007). Garrison \& Kanuka (2004) consideram o B-learning como um processo de integração refletida que leva à escolha das caraterísticas de cada um dos regimes, que se adaptam melhor às necessidades do projeto de ensino-aprendizagem que se pretende levar a cabo.

As plataformas de aprendizagem ou sistemas de gestão da aprendizagem são, normalmente, o suporte tecnológico usado para a vertente online como, por exemplo, a plataforma Moodle. Estas possuem um vasto leque de aplicações, nomeadamente, salas de chat, fóruns de discussão, videoconferência, blogues, wikis, e-portfolios, arquivamento e partilha de ficheiros. Estes sistemas têm tido larga aplicação no campo do ensino online, no entanto, com o aparecimento da computação em nuvem, a Google disponibiliza um conjunto de serviços gratuitos para a educação sob a designação de Google Apps, com nomeação de domínio e gestão da própria Escola. Estes serviços não impõem limite máximo no número de utilizadores nem na capacidade de armazenamento. Incluem drives virtuais para armazenamento e partilha de pastas e documentos, para além de um conjunto de ferramentas de produtividade online em regime colaborativo (e.g. editor de documentos de texto, diapositivos, folha de cálculo, formulários, desenho, mapa de conceitos entre outros). O Google Apps inclui também funcionalidades de serviço de mensagens multimédia, correio eletrónico, criação e partilha de websites e blogues, gestor de grupos de debate, e gestão de agenda de eventos. Moura (2007) afirma que as ferramentas disponibilizadas pela Google "estão a revelar-se verdadeiramente extraordinárias em vários domínios mas sobretudo na educação" (p. 2). Em agosto de 2014 a Google lançou o serviço Classroom, para as escolas com Google Apps. Este serviço possibilita a criação de turmas e a gestão, marcação, avaliação e reformulação de trabalhos dos alunos pertencentes à turma. Por tudo isto, o conjunto dos serviços disponíveis permite pensar no Google Apps como mais uma plataforma de apoio ao ensino em regime de E-learning ou B-learning.

\subsection{Recursos Educativos Digitais}

Recurso Educativo Digital (RED) é um conceito, que embora expresso diferentemente por vários autores, reúne o consenso sobre o facto de serem produzidos com fins educativos, portanto, com preocupações pedagógicas e didáticas. Como entidades digitais (Ramos, Teodoro \& Ferreira, 2011) podem assumir a forma de jogos educativos, vídeos, programas tutoriais, páginas web, ou seja, todo o tipo de recursos armazenados em suporte digital. O conceito de RED é indissociável de conceito de Objeto de Aprendizagem (OA) ou Learning Objects. Estes isoladamente ou em conjunto, fazem parte de um RED. Os OA têm particularidades que os distinguem, como sejam a 
granularidade - sendo que um "grânulo é a mais pequena unidade educativa capaz de alcançar um objetivo de aprendizagem" (Miranda, 2009, p. 103), a interoperabilidade no que respeita aos suportes e software, a adaptabilidade ao público-alvo, a usabilidade do objeto pelo estudante e a modularidade (Sousa \& Coutinho, 2009). Esta última característica permite a manipulação, no que se refere aos possíveis e diferentes arranjos sequenciais de vários OA, ou seja, a possibilidade de variar a sua organização, quando usados em diferentes contextos de ambiente de aprendizagem, adaptando-os a diferentes perfis de estudantes e a diferentes objetivos de aprendizagem (Moreira \& Monteiro, 2012). Os RED e os OA podem ter vários tipos de suporte, nomeadamente físicos com gravação digital, CDs, DVDs, etc., ou virtuais como páginas disponíveis na Internet. Podem encontrar-se RED alojados em páginas pessoais, de professores, escolas, empresas e grupos de pessoas interessadas na temática. Na generalidade, estes suportes virtuais têm por fim a divulgação de recursos de áreas específicas ou para utilização em atividades letivas concretas. Existem outros locais de alojamento, normalmente designados por repositórios, cujo objetivo é o de disponibilizarem os RED para utilização das comunidades educativas, podendo o acesso ser, ou não, gratuito.

\subsection{Teoria Cognitiva da Aprendizagem Multimédia}

A Teoria Cognitiva da Aprendizagem Multimédia (TCAM) tem por base a Teoria da Carga Cognitiva, com a particularidade de ser mais especializada na aprendizagem com palavras e imagens (Mayer \& Moreno, 2010) e assenta em três pressupostos: o pressuposto dos canais duplos - de acordo com a Teoria da Dupla Codificação de Paivio (1986), os seres humanos têm dois canais para processar separadamente estímulos visuais/pictóricos e estímulos auditivos/verbais; o pressuposto da capacidade limitada de processamento em cada canal em simultâneo - há um limite para a quantidade de informação que é possível processar ao mesmo tempo nos dois canais; e o pressuposto do processamento ativo, que implica que se executem processos cognitivos durante a aprendizagem, designadamente de escolha, organização e integração da informação.

Mayer (2009) considera três tipos de memória envolvidos no processo cognitivo: Memória sensorial; Memória de trabalho; Memória de longo prazo. A memória sensorial permite, por um período de tempo muito curto, que as imagens, sons e palavras que são percecionadas pelos respetivos órgãos recetores (olhos e ouvidos), sejam retidas e passem à memória de trabalho para serem processadas (Baddeley, 1999), nomeadamente,

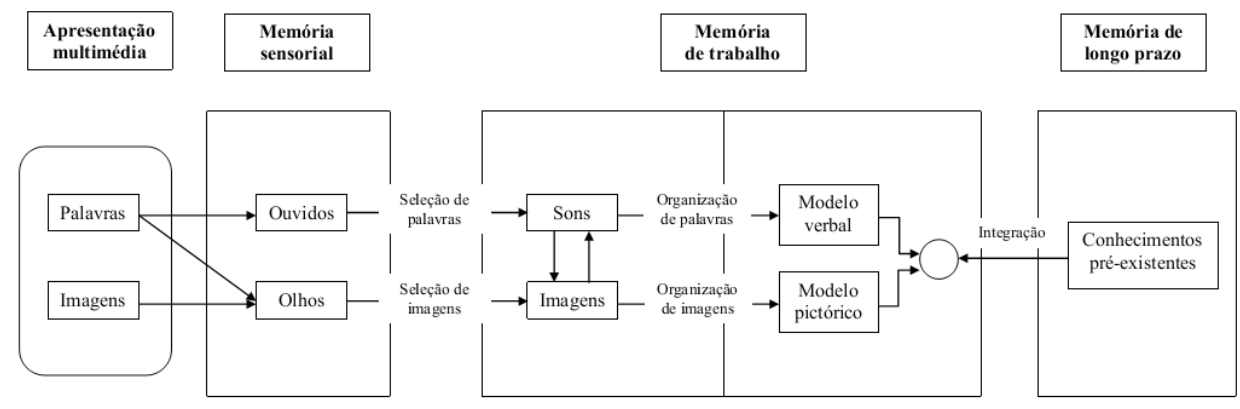

Figura 1 - Teoria cognitiva da aprendizagem multimédia (Mayer, 2009) 
organizadas em modelos verbais e visuais. Finalmente, ainda na memória de trabalho, são integradas com conhecimentos prévios (cf. Figura 1).

Durante a aprendizagem, de acordo com a TCAM, ocorrem cinco processos cognitivos (cf. Figura 1): escolha de palavras relevantes; escolha de imagens relevantes; organização das palavras selecionadas; organização das imagens selecionadas; integração das representações pictóricas e verbais, decorrentes das organizações anteriores. Numa apresentação multimédia típica são apresentadas informações nos formatos: sons nãoverbais, palavras ditas; palavras escritas; e imagens estáticas ou animadas. Após terem sido percecionadas pelos respetivos órgãos, palavras escritas e imagens pelos olhos, palavras ditas e sons não-verbais pelos ouvidos, ficam retidas por breves instantes na memória sensorial. Na passagem para a memória de trabalho dão-se dois processos de seleção: de imagens e palavras escritas relevantes no canal visual; sons não-verbais e palavras proferidas relevantes no canal verbal. No entanto, o estudante pode converter texto escrito em narrado para ser processado no canal verbal. Esta seleção permite à memória de trabalho organizar a informação selecionada em modelos verbais e pictóricos de acordo com a sua origem. Os processos de organização não são arbitrários, refletindo antes, um esforço de construção de estruturas simples e com sentido. Finalmente, após estabelecidos os modelos verbal e pictórico, em conjunto com conhecimentos prévios armazenados na memória de longo prazo, tem lugar uma "representação integrada na qual os elementos e relações correspondentes de cada modelo são inscritos no outro" (Mayer, 2009). Durante uma apresentação multimédia há uma sucessão de ciclos de aplicação dos processos descritos. O êxito na aprendizagem é conseguido através da monitorização e coordenação dos cinco processos, sendo determinante uma atitude de empenho e envolvimento por parte do estudante.

O papel da TCAM é o da criação de um quadro teórico que permita o estabelecimento de princípios e técnicas a aplicar na execução de recursos multimédia que promovam a aprendizagem, atendendo às limitações do processo de cognição no ser humano. Mayer e Moreno (1998), no início dos seus estudos, estabeleceram cinco grandes princípios "principles of multimedia design", após a realização de extensa investigação aplicada em condições controladas e análise quantitativa, a aplicar na elaboração de recursos multimédia a usar na instrução. Pretendia-se, deste modo, verificar a existência da redução da carga cognitiva ineficaz para promover a aprendizagem. Mayer e Moreno (1998) designaram como efeito multimédia, a melhoria de resultados obtidos pelos estudantes incluídos no grupo sujeito à aplicação dos princípios na elaboração dos recursos apresentados em comparação com aqueles que estão incluídos no grupo que não esteve sujeito à aplicação dos princípios.

Mayer, no decorrer das investigações subsequentes sobre como melhorar a aprendizagem em ambientes multimédia, aumentou o número de princípios para doze. A TCAM foi expandida e passou a incluir um modelo triplo de processamento cognitivo (Mayer, 2009a) relacionado com as cargas cognitivas identificadas por Sweller et al. (1998): processamento ineficaz (extraneous processing) - relacionado com a carga cognitiva ineficaz; processamento principal (essential processing) - relacionado com a carga cognitiva intrínseca; e processamento gerador (generative processing) - relacionado com a carga cognitiva adequada. Os doze princípios foram então organizados em três grupos de produção de efeitos (cf. Tabela 2) (Mayer, 2008; Mayer, 2009a): redução 
do processamento ineficaz - processo cognitivo que não faz parte dos objetivos de aprendizagem e que depende de como os conteúdos são apresentados; gestão do processamento principal - processo cognitivo que abarca processos como a seleção de imagens relevantes e depende da complexidade dos conteúdos apresentados; e promoção do processamento gerador - envolve processos mais profundos como a organização e integração, dependente da motivação do estudante.

Redução do processamento ineficaz

1-Princípio da coerência Os estudantes aprendem melhor se forem excluídos texto, som e imagem, que não estejam relacionados com o objetivo de aprendizagem

2- Princípio da sinalização Os estudantes aprendem melhor quando texto e imagem, essenciais à prossecução do objetivo de aprendizagem, forem sinalizados

3-Princípio da redundância

Os estudantes aprendem melhor a partir de imagens e texto narrado, que a partir de imagens e texto escrito e narrado

4- Princípio da contiguidade Os estudantes aprendem melhor quando texto e imagem correspondente espacial forem apresentados juntos, em vez de afastados

5- Princípio da contiguidade temporal

Os estudantes aprendem melhor quando forem apresentados simultaneamente o texto e imagem correspondente, em vez de sucessivamente

Gestão do processamento principal

\begin{tabular}{ll}
\hline 6- Princípio da segmentação & $\begin{array}{l}\text { Os estudantes aprendem melhor quando o conteúdo multimédia for } \\
\text { apresentado em segmentos organizados de acordo com a capacidade do } \\
\text { utilizador, em vez de uma unidade contínua }\end{array}$
\end{tabular}

7- Princípio do conhecimento prévio

Os estudantes aprendem melhor quando antes de se apresentar o conteúdo multimédia principal, se apresentarem os conceitos básicos necessários para a sua compreensão

8- Princípio da modalidade Os estudantes aprendem melhor quando se apresenta o conteúdo multimédia usando imagens e texto narrado, em vez de imagens e texto escrito

Promoção do processamento gerador

\begin{tabular}{ll}
\hline 9- Princípio multimédia & $\begin{array}{l}\text { Os estudantes aprendem melhor com texto e imagem, em vez de apenas } \\
\text { texto }\end{array}$ \\
\hline $\begin{array}{l}\text { 10- Princípio da } \\
\text { personalização }\end{array}$ & $\begin{array}{l}\text { Os estudantes aprendem melhor quando o conteúdo multimédia é } \\
\text { apresentado com discurso narrado em estilo informal, em vez de narrado } \\
\text { em estilo formal }\end{array}$ \\
\hline 11- Princípio da voz & $\begin{array}{l}\text { Os estudantes aprendem melhor se o discurso for narrado em voz humana, } \\
\text { em vez de narrado com voz sintetizada }\end{array}$ \\
\hline & $\begin{array}{l}\text { Os estudantes não aprendem necessariamente melhor se durante a } \\
\text { narração de um conteúdo multimédia for apresentada a imagem do } \\
\text { narrador no monitor }\end{array}$ \\
\hline
\end{tabular}

Tabela 2 - Os doze princípios multimédia de Mayer (2009a) organizados em três grupos de produção de efeitos 
O trabalho de Richard Mayer e dos seus colegas relativamente à verificação empírica dos princípios da TCAM é contínuo. Assim, os doze princípios sustentados por Mayer (2009a) passaram para quinze (Mayer, 2014). O princípio da imagem deixou de existir, uma vez que os resultados obtidos da investigação levaram a concluir que a utilização do princípio num conteúdo multimédia não melhorava as aprendizagens. Por outro lado, surgiram quatro novos princípios como consequência da procura de estratégias que possam promover o processamento gerador: Embodiment principle - fazer uso de elementos humanos, como, gestos, expressões faciais, etc.; Guided discovery learning principle - proporcionar pistas e feedback à medida que o estudante resolve os problemas; Self-explanation principle - solicitar ao estudante para explicar a si próprio o conteúdo aprendido; Drawing principle - solicitar ao estudante para desenhar sobre o conteúdo aprendido.

\section{Metodologia}

No desenvolvimento desta experiência estiveram envolvidos nove professores e catorze alunos de uma turma do Curso Profissional de Técnico de Construção Civil. A turma encontrava-se no último ano da sua formação, ano em que os alunos realizaram a sua PAP, que se desenvolveu em quatro fases ao longo do ano letivo: $1 .^{\text {a }}$ fase - iniciaram em outubro os procedimentos de candidatura, entregando-a em dezembro; $2 .^{\mathrm{a}}$ fase o projeto desenvolveu-se de janeiro até final de maio; $3 .^{\mathrm{a}}$ fase - fizeram a entrega do relatório; $4 \cdot^{\mathrm{a}}$ fase - alguns alunos apresentaram e defenderam publicamente os seus relatórios em julho (1. ${ }^{\mathrm{a}}$ época) e outros, em novembro (2. ${ }^{\mathrm{a}}$ época). Os alunos, quatro do sexo feminino e dez do masculino, na sua maioria tinham 20 anos e concluíram o $3 .^{\circ}$ ciclo de escolaridade frequentando um $\mathrm{CEF}$, pois tiveram duas a três retenções durante a frequência do ensino básico, sem nunca terem, no entanto, abandonado a escola. Os professores pertenciam às três áreas do currículo: quatro da área sociocultural, dois da área científica, como professores de apoio ao acompanhamento; três da área técnica, como professores acompanhantes, nos quais se inclui um dos autores deste artigo.

A necessidade de desenvolvimento desta experiência decorreu da identificação, pelos professores acompanhantes ao longo de vários anos de atividade, de algumas dificuldades no acompanhamento do processo PAP e no desenvolvimento, pelos alunos, das atividades que lhe estão associadas. Assim, pretendeu-se ultrapassar essas dificuldades, tentando melhorar a: (a) Interação entre o aluno que desenvolve o trabalho de PAP e o respetivo professor acompanhante; (b) Envolvência por parte do aluno no seu processo de preparação, desenvolvimento e apresentação do processo de PAP; (c) Transparência no processo de acompanhamento de PAP; (d) Eficácia do processo de acompanhamento de PAP; (e) Qualidade dos projetos de PAP no que se refere ao respeito pelas normas e regulamentos, processos e técnicas de pesquisa online e respeito pelos Direitos de Autor.

A metodologia de investigação adotada para desenvolver este projeto foi a metodologia de desenvolvimento, também conhecida por Design-Based Research, uma vez que se tratou de uma investigação empírica num ambiente complexo, onde existe um forte envolvimento do investigador com a comunidade escolar, na procura e experimentação de soluções que contribuam para a resolução dos problemas encontrados. Foi estabelecido um desenvolvimento em quatro fases, ligadas entre si de modo sequencial (cf. Figura 2). 
Devido ao caráter iterativo da metodologia, houve a possibilidade de criação de ciclos que se repetiram até se terem obtido os resultados considerados ótimos, sobretudo no que respeita à criação dos RED.

$\mathrm{Na}$ recolha de dados recorreu-se quer a métodos e técnicas quantitativas - e.g. aplicação de questionários, quer qualitativas - análise de atas e outros registos formais que fazem parte do processo de PAP e troca de impressões informais com os intervenientes no projeto. Pretendeu-se, sobretudo, diminuir a carga acrescida resultante da participação no projeto e, também, minimizar a hipotética perturbação que seria causada no contexto existente, pela excessiva formalidade, perdendo-se alguma genuinidade nos dados obtidos.

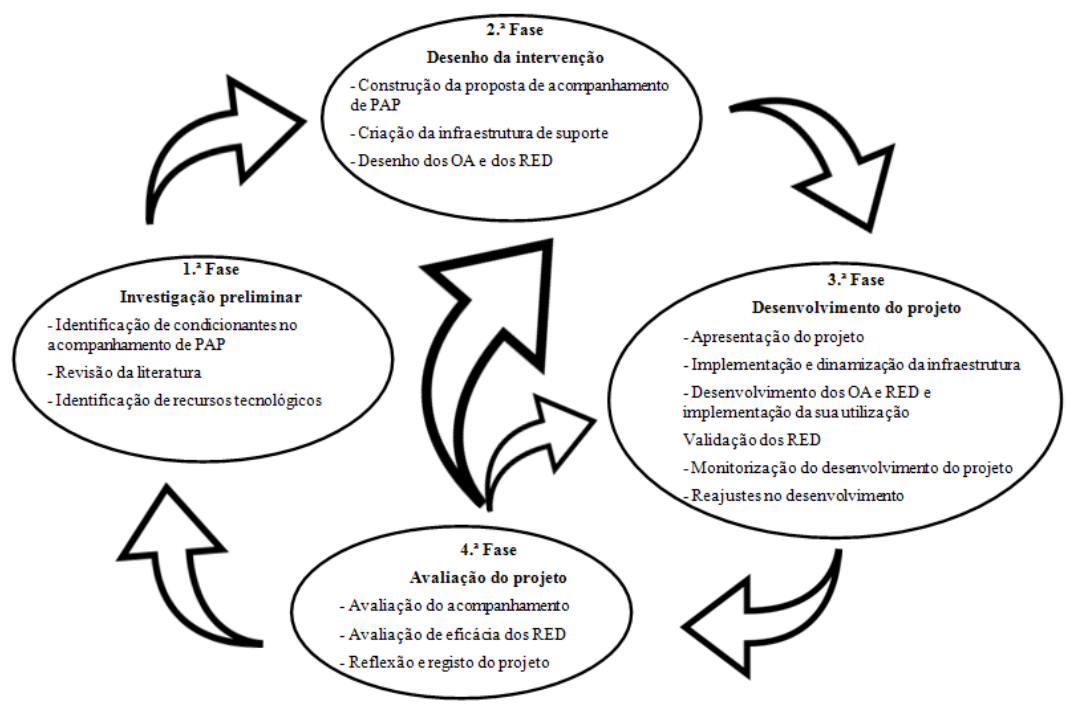

Figura 2. - Desenho do projeto

\section{Desenvolvimento}

O projeto iniciou-se no final do ano letivo anterior ao desenvolvimento da PAP, com a identificação das dificuldades, sentidas por alunos e professores, do processo de acompanhamento e de desenvolvimento desta prova. Para esse efeito, aplicaramse questionários aos alunos que terminaram as suas PAP nesse ano e aos professores que os acompanharam e analisaram-se os documentos resultantes do processo. Os dados obtidos vieram confirmar as perspetivas resultantes das conversas tidas com os professores envolvidos em anteriores processos de PAP (cf. Tabela 3). Com base naquelas dificuldades desenhou-se o projeto da experiência, que implicou a criação de uma infraestrutura de acompanhamento do processo de PAP daquela turma, em regime de B-learning e o desenvolvimento de um conjunto de RED para responder à necessidade de apresentação de conteúdos considerados essenciais à realização da PAP. 


\begin{tabular}{|c|c|}
\hline Dificuldade & Situação \\
\hline $\begin{array}{l}\text { Tempo de acompanhamento diminuto e } \\
\text { dificuldade em reunir com os alunos para } \\
\text { avaliação do processo de PAP }\end{array}$ & $\begin{array}{l}\text { Não existiam aulas de apoio à PAP no horário letivo; } \\
\text { Não existe horário, livre para além do horário letivo, } \\
\text { devido a ausência de transporte. }\end{array}$ \\
\hline $\begin{array}{l}\text { Dificuldades de comunicação entre aluno e } \\
\text { professor acompanhante }\end{array}$ & $\begin{array}{l}\text { Comunicação face a face apenas nos intervalos ou durante } \\
\text { as aulas das disciplinas do currículo } \\
\text { Comunicação online apenas através de email }\end{array}$ \\
\hline $\begin{array}{l}\text { Dificuldade de acesso e de organização do } \\
\text { trabalho efetuado }\end{array}$ & $\begin{array}{l}\text { Textos desenvolvidos em processador de texto offline } \\
\text { Existência de várias cópias deficientemente nomeadas } \\
\text { Inexistência de histórico de alterações no processador }\end{array}$ \\
\hline Perda do trabalho realizado & Inexistência de cópias de segurança \\
\hline $\begin{array}{l}\text { Dificuldade na aplicação de normas e } \\
\text { regulamentos de PAP }\end{array}$ & $\begin{array}{l}\text { Disponibilização de normas e regulamentos em papel } \\
\text { Falta de recursos didáticos }\end{array}$ \\
\hline Dificuldades no processo de pesquisa online & $\begin{array}{l}\text { Ausência de conteúdos curriculares com incidência em } \\
\text { processos de pesquisa online }\end{array}$ \\
\hline $\begin{array}{l}\text { Falta de sensibilidade no respeito pelos } \\
\text { direitos dos autores }\end{array}$ & $\begin{array}{l}\text { Ausência de conteúdos curriculares relativos ao Direito de } \\
\text { Autor }\end{array}$ \\
\hline $\begin{array}{l}\text { Desconhecimento de ferramentas e regras de } \\
\text { apresentação multimédia }\end{array}$ & $\begin{array}{l}\text { Valorização quase exclusiva do Microsoft PowerPoint } \\
\text { como ferramenta de edição de diapositivos } \\
\text { Ausência de conteúdos curriculares sobre comunicação } \\
\text { multimédia }\end{array}$ \\
\hline Desconforto na apresentação pública & Desconhecimento de técnicas de descontração \\
\hline
\end{tabular}

Tabela 3 - Dificuldades constatadas antes da experiência

\subsection{Plataforma de Apoio ao Acompanhamento do Processo de PAP}

Atendendo à dispersão geográfica e à ocupação da maior parte do dia com tempos letivos, o desenvolvimento do projeto de PAP faz-se, na sua maior parte, no pouco tempo disponível, depois das aulas. Assim, a solução implementada foi a de disponibilizar um sistema de acompanhamento das PAP em regime de B-learning, com a componente online sustentada pela utilização do Google Apps, uma vez que já estava a ser usado pela Escola. Como afirmam Bottentuit Junior \& Coutinho (2009) os ambientes de aprendizagem online "organizados tradicionalmente em torno de plataformas de aprendizagem, começam a ceder terreno aos novos recursos e serviços gratuitos disponíveis na Web a que todos podem aceder sem grandes conhecimentos a nível de informática” (p. 64).

A componente online foi estruturada, sobretudo, para responder às várias dificuldades que os alunos sentem no decorrer do projeto de PAP, seja de acompanhamento assíduo, seja de disponibilização de recursos. Esta componente desenvolveu-se em duas vertentes: Disponibilização de referências fiáveis e conteúdos de suporte ao desenvolvimento da PAP, repositório de materiais recolhidos e backup de conteúdos produzidos; Acompanhamento individual feito durante o processo de escrita e desenvolvimento de atividades decorrentes do projeto de PAP através de meios de comunicação expeditos, síncrono e assíncrono, entre todos os envolvidos no projeto e suporte para as atividades desenvolvidas no âmbito do acompanhamento de PAP. 
Como metodologia de trabalho criou-se, na Drive do Coordenador, uma pasta para cada par aluno-professor acompanhante, que se partilhou com as respetivas Drives individuais de alunos e professores acompanhantes. Garantiu-se, deste modo, a acessibilidade constante ao trabalho desenvolvido e, ao mesmo tempo, a privacidade dos alunos, dado que só os elementos envolvidos no acompanhamento da PAP e cada aluno, tinham conhecimento dos respetivos trabalhos. Nessa pasta partilhada foram colocados, pelo coordenador e professores acompanhantes, elementos bibliográficos sugeridos, podendo os alunos acrescentar elementos recolhidos por si nas pesquisas efetuadas. Criaram-se ainda documentos parciais, por capítulo da Candidatura, possibilitando a sua edição, no processador de texto da Drive, pelos alunos e acompanhada a sua execução pelos professores acompanhantes. Após a elaboração e aprovação das candidaturas de PAP, dado que os alunos já se tinham apoderado da tecnologia, foram eles que criaram as novas pastas e documentos para o desenvolvimento do Projeto de PAP, que partilharam com o coordenador e professores acompanhantes. O acompanhamento foi realizado de modo síncrono e assíncrono, pelos respetivos professores acompanhantes, coordenador do curso e, no final, pelo professor acompanhante de apoio, usando as ferramentas de comentário e de chat. Outra ferramenta de acompanhamento da atividade do aluno foi o separador "Atividade" na janela principal da Drive, que dá informação organizada e permanentemente atualizada sobre a atividade relativa a uma pasta ou ficheiro. Após os documentos parciais constituintes da Candidatura estarem todos elaborados, os alunos descarregaram os ficheiros para os seus computadores pessoais, reunindo-os num único documento e formatando-o no Microsoft Word, dadas as limitações a nível da formatação que existiam no processador de texto do Google Apps.

A componente presencial impôs-se pela necessidade de contato direto e imediato com as dificuldades mais básicas dos estudantes. Nestas aulas presenciais foi efetuado, com os alunos, um trabalho de preparação para a realização de pesquisa bibliográfica online e em biblioteca, definição de objetivos, planificação de atividades, análise e síntese de textos técnicos, estruturação e formatação de textos. Foram também desenvolvidas aplicações práticas decorrentes dos conteúdos expostos nos RED disponibilizados. Sumariamente, fez-se a preparação dos alunos para que desenvolvessem o seu processo de PAP da forma o mais autónoma possível.

\subsection{Desenvolvimento do Conjunto de RED}

A execução e disponibilização dos RED foram faseadas em harmonia com as fases de desenvolvimento da PAP: Candidatura; Projeto; Relatório; Apresentação e Defesa. Simultaneamente com o decurso de cada fase de PAP, identificavam-se, nas sessões presenciais com os alunos, as necessidades de informação e construíam-se os OA e o recurso digital correspondente a essa fase de PAP. Deste modo, foram desenvolvidos sequencialmente os RED: “Apoio à Candidatura de PAP”; “Apoio ao Projeto de PAP”; "Apoio à Apresentação da PAP”. Durante o desenvolvimento do terceiro recurso, verificou-se que o acesso aos vários recursos era pouco eficiente e que haveria vantagem na sua reunião num único endereço eletrónico, criando-se, para o efeito, um Portal para acesso aos recursos (http://cciv84.wix.com/apoioapap). Para construir os RED e o Portal utilizou-se a ferramenta online de construção de páginas em HTML 5, "Wix" (https://pt.wix.com). Esta opção foi tomada em função da gratuitidade, facilidade de utilização e, no nosso entender, qualidade profissional dos resultados permitidos. 
Relativamente à estrutura e aspeto gráfico dos RED e Portal pretendeu criar-se a ideia de unidade dos recursos, através de um grafismo e estrutura iguais e ainda um interface simples, com funções facilmente reconhecíveis e intuitivas. Os conteúdos a transmitir nos RED e nos OA são sobretudo enquadramentos legais e regulamentares, e informações sobre técnicas, tecnologias e atitudes a utilizar no decurso do processo de PAP (cf. Tabela 4). Assim, na sua composição optou-se pela disponibilização de OA com caraterísticas multimédia de caráter informativo, recorrendo a hiperligações para

\begin{tabular}{|c|c|c|}
\hline RED & Página & OA (Descrição) \\
\hline 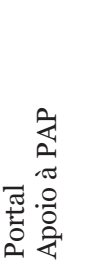 & $\begin{array}{l}\text { A PAP } \\
\text { Recursos da PAP } \\
\text { Sobre este Portal }\end{array}$ & $\begin{array}{l}\text { Texto de enquadramento da PAP no curso } \\
\text { Texto de enquadramento da PAP no currículo } \\
\text { Vídeo narrado, com mapa concetual relativo a intervenientes, } \\
\text { organização e operacionalização do processo de PAP } \\
\text { Texto de justificação dos RED } \\
\text { Ligação aos RED construídos para cada uma das fases de PAP } \\
\text { Texto com algumas reflexões sobre as razões que levaram à } \\
\text { existência desta experiência }\end{array}$ \\
\hline 趂 & $\begin{array}{l}\text { Candidatura } \\
\text { Candidatura-Preparação } \\
\text { Candidatura-Execução }\end{array}$ & $\begin{array}{l}\text { Texto explicativo sobre este RED e sobre as melhores condições de } \\
\text { visionamento dos OA } \\
\text { Vídeo narrado, com mapa concetual relativo a conceitos a considerar } \\
\text { na preparação da elaboração da Candidatura à PAP } \\
\text { Vídeo narrado, com mapa concetual relativo a conceitos relativos } \\
\text { aos elementos que constituem a Candidatura à PAP }\end{array}$ \\
\hline 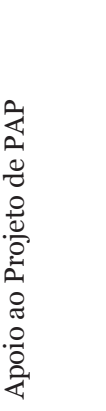 & $\begin{array}{l}\text { O Projeto de PAP } \\
\text { Pesquisar online }\end{array}$ & $\begin{array}{l}\text { Texto sobre a metodologia de pesquisa e recolha e seleção da } \\
\text { informação necessária ao desenvolvimento do projeto } \\
\text { Texto introdutório sobre o conceito de pesquisa } \\
\text { Infográfico com hiperligações sobre a história dos motores de busca } \\
\text { na Internet } \\
\text { Flipbook com variadas técnicas básicas e avançadas e vários } \\
\text { recursos para efetuar pesquisa online } \\
\text { Vídeo sobre os direitos do autor e a licença para usar a sua obra } \\
\text { Vídeo / apresentação de diapositivos explicativos da filosofia e } \\
\text { funcionamento das licenças Creative Commons } \\
\text { Mapa concetual com hiperligações, onde se relacionam os conceitos } \\
\text { relativos aos direitos dos autores }\end{array}$ \\
\hline 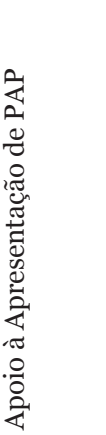 & $\begin{array}{l}\text { Apresentação e defesa } \\
\text { da PAP } \\
\text { Construir a apresentação }\end{array}$ & $\begin{array}{l}\text { Texto sobre a ideia de Apresentação perante público } \\
\text { Flipbook, onde se apresentam algumas ferramentas de criação/ } \\
\text { edição de diapositivos eletrónicos } \\
\text { 10 dos mais importantes princípios estabelecidos por Richard } \\
\text { Mayer, no âmbito da TCAM } \\
\text { Apresentação com metodologia de trabalho, estrutura e composição } \\
\text { gráfica de uma apresentação de diapositivos } \\
\text { Texto sobre atitudes antes e durante uma apresentação } \\
\text { Flipbook sobre o método de preparação de uma apresentação } \\
\text { pública com projeção de diapositivos } \\
\text { Apresentação em Prezi sobre atitudes e técnicas de relaxamento } \\
\text { imediatamente antes e durante a apresentação pública }\end{array}$ \\
\hline
\end{tabular}

Tabela 4 - Descrição sintética dos RED 
complementar as temáticas tratadas. Para o efeito foram utilizadas várias tipologias, nomeadamente vídeos, apresentações de diapositivos, livros eletrónicos e imagens com hiperligações e com percursos de visualização e leitura previamente estabelecidos, permitindo, no entanto, que o utilizador controle o processo. A principal linha condutora, na construção daqueles elementos criados para a aprendizagem, foi o respeito pelos princípios integrantes da TCAM. Assim, utilizou-se o menos possível o texto escrito, recorreu-se à narração e explicitação de conceitos através de imagens estáticas e dinâmicas, promovendo o processamento gerador. Os conteúdos foram produzidos de modo a não incluírem elementos não diretamente relacionados com o tema e a respeitar os princípios da contiguidade, reduzindo o processamento ineficaz. Os conteúdos foram também repartidos em unidades mais pequenas e apelando a conhecimentos já anteriormente adquiridos, permitindo ao aluno gerir o processamento principal, criando padrões reconhecíveis e, assim, reduzir a carga cognitiva extrínseca.

\section{Conclusões}

A experiência serviu sobretudo para introduzir novas metodologias de trabalho no processo de acompanhamento das PAP, atendendo à realidade concreta da escola onde se desenvolveu o estudo. Os meios disponibilizados pretenderam facilitar o acompanhamento, permitindo uma avaliação verdadeiramente contínua e formativa dos trabalhos das PAP dos alunos. Ao mesmo tempo, possibilitou-se aos alunos a elaboração de trabalhos melhor estruturados e mais bem fundamentados, por via de um maior conhecimento e envolvência no processo e, também de maior eficácia na pesquisa bibliográfica online e de respeito pelos Direitos de Autor.

A utilização do Google Apps, como plataforma de apoio ao acompanhamento das PAP, permitiu:

Facilitar a interação aluno-professor acompanhante, através da possibilidade do acompanhamento permanente do trabalho executado pelo aluno no editor de documentos e através de uma comunicação e partilha célere, usando o chat presente no editor de documentos e o e-mail e ainda usando a ferramenta de comentários do editor;

Maior envolvência dos alunos e professores acompanhantes, através de meios de comunicação céleres e expeditos, eliminando as barreiras impostas pela distância física, fora dos tempos letivos, entre os participantes no processo de PAP e permitindo que houvesse um acompanhamento intensivo dos trabalhos realizados, a qualquer hora, nomeadamente, expondo ideias, sugerindo alterações e disponibilizando novas pistas para pesquisa de material bibliográfico;

Processo mais transparente através do registo do progresso do trabalho, nomeadamente das alterações, sugestões e indicações de correção pelo professor acompanhante e das perguntas, respostas e correções efetuadas pelo aluno, permitindo, deste modo, que os intervenientes diretos, ou seja, o aluno, o professor acompanhante e o coordenador do curso, estejam na posse de todos os elementos necessários a uma verdadeira avaliação formativa.

Aumentar a eficácia do acompanhamento através da possibilidade de, a qualquer momento, estar a par do desenvolvimento dos trabalhos sem haver necessidade de troca 
de ficheiros em e-mail, pen-drive ou outros dispositivos, dar feedback constante sobre a evolução dos trabalhos, bem como esclarecer dúvidas em tempo real ou de forma assíncrona.

Melhorar a acessibilidade e facilidade de atualização dos recursos, nomeadamente de normas, regulamentos e outros documentos relativos à PAP, partilhando-os com os alunos que passaram a poder consultá-los online, ou descarregálos para utilização offline.

A construção e disponibilização na Internet dos recursos digitais sobre as temáticas consideradas fulcrais, permitiu aumentar a qualidade dos projetos, e treinar competências de caráter transversal, tendo ficado patente através da: Correta interpretação e aplicação da estrutura regulamentar da PAP, não tendo havido percalços regulamentares; Melhoria das capacidades de pesquisa online, demonstrada pela variedade de fontes significativas utilizadas no desenvolvimento dos Relatórios; Melhoria dos materiais de apresentação, atitude e competência de apresentação na Apresentação e Defesa de PAP, mostradas através de diapositivos equilibrados e de fácil leitura, bem como de posturas menos tensas e maior fluência na oralidade.

Verificou-se, no entanto, relativamente ao respeito pelos Direitos de Autor que, apesar das estratégias de esclarecimento e sensibilização aplicadas e dos conteúdos presentes nos RED terem sido trabalhados com os alunos, estes não corresponderam às expetativas. Estas falhas notaram-se nos Relatórios de PAP, por algumas ausências ao nível das citações e referências. Queremos referir que, este é um problema que deverá ser ultrapassado através da introdução desta temática logo no início dos cursos, uma vez que, a cultura do copy-paste, do download e da fotocópia, está enraizada na cultura popular, ou seja é um problema cultural que urge combater por via da educação.

Numa apreciação global da experiência, acreditamos que, para os alunos e professores que participaram neste estudo, a experiência foi positiva, abrindo deste modo a possibilidade para a realização de outras experiências similares, nesta Escola ou em outras escolas profissionais. As evidências assim o demonstram. O maior fator de sucesso foi, sem dúvida, o facto de ainda hoje esse acompanhamento estar a ser feito nesta Escola, nos moldes definidos por esta experiência. Ou seja, continua a usar-se o Google Apps como plataforma de edição de documentos para a PAP, para que exista um acompanhamento intensivo e constante dos trabalhos dos alunos e os RED produzidos são, também, fonte de informação utilizada para a orientação e acompanhamento do processo de PAP.

\section{Referências}

Abreu, A., Rocha, Á., Cota, M. P., \& Carvalho, J. V. (2015). Caderneta Eletrónica no Processo Ensino-Aprendizagem: Visão de Professores e Pais de alunos do ensino Básico e Secundário. RISTI - Revista Ibérica de Sistemas e Tecnologias de Informação, (16), 108-128.

Bottentuit Junior, J. \& Coutinho, C. (2009). Do E-learning tradicional ao E-learning 2.o. Prima.com, 8, 63-76. Retirado de http://revistas.ua.pt/index.php/prismacom/ article/download/688/pdf. 
Coutinho, C. \& Alves, M. (2010). Educação e sociedade da aprendizagem: um olhar sobre o potencial educativo da Internet. Revista de Formación e Innovación Educativa Universitaria. 3 (4), 206-225. Retirado de http://hdl.handle.net/1822/11229

Coutinho, C., \& Bottentuit Junior, J. (2007). A complexidade e os modos de aprender na sociedade do conhecimento. Retirado de http://hdl.handle.net/1822/6501

Garrison, D. R., \& Kanuka, H. (2004). Blended learning: Uncovering its transformative potential in higher education. The Internet and Higher Education, 7(2), 95-105. Retirado de http://www.celtelearning.org/images/uploads/expertise/ GarrisonKanuka2004.pdf

Jonassen, D. H. (2007). Computadores, Ferramentas Cognitivas. Desenvolver o pensamento crítico nas escolas. Porto: Porto Editora.

Mayer, R. (2008). Applying the science of learning: evidence-based principles for the design of multimedia instruction. American psychologist, 63 (8), 760-769. doi: 10.1037/o003-066X.63.8.760Mayer, R. (2009). Teoria cognitiva da aprendizagem multimédia. In G. L. Miranda (Org.). Ensino online e aprendizagem multimédia (pp. 207-237). Lisboa: Relógio d’Água Editores.

Mayer, R. (2009a). Multimédia learning - Second edition. Cambridge: Cambridge University Press.

Mayer, R. (2014). Cognitive theory of multimedia learning. In R. E. Mayer (Ed.) The Cambridge handbook of multimedia learning - Second edition (pp. 43-71). Cambridge: Cambridge University Press.

Mayer, R., Moreno, R. (1998). A cognitive theory of multimedia learning: implications for design principles. Retirado de http://esoluk.co.uk/calling/pdf/chi.pdf

Mayer, R. \& Moreno, R. (2010). Techniques that reduce extraneous cognitive load and manage intrinsic cognitive load during multimédia learning. In Jan L. Plass et al. (Eds.). Cognitive load theory (pp. 131-152). Cambridge: Cambridge University Press.

Miranda, G. L. (2009). Concepção de conteúdos e cursos online. In G. L. Miranda (Org.). Ensino online e aprendizagem multimédia (pp. 81-110). Lisboa: Relógio d’Água Editores.

Moreira, J. A. \& Monteiro, A. (orgs.) (2012). Ensinar e aprender online com tecnologias digitais: abordagens teóricas e metodológicas. Porto: Porto Editora.Moura, A. (2007). Projecto Etwinning através da Web 2.0: uma experiência em língua estrangeira. In P. Dias; C.V. Freitas; B. Silva; A. Osósio \& A. Ramos (orgs.), Actas da V Conferência Internacional de Tecnologias de Informação e Comunicação na Educação: Desafios 2007/ Challenges 2007 (pp. 253-256). Braga: Universidade do Minho. Retirado de http://hdl.handle.net/11328/461

Ramos, J., Teodoro, V. \& Ferreira, F. (2011). Recursos educativos digitais. Reflexões sobre a prática. Cadernos SACAUSEF - Recursos educativos digitais: que futuro, 7, 11-34. Ministério da Educação /DGIDC. Retirado de http://hdl.handle. net/10174/5051 
Singh, H., \& Reed, C. (2001). A white paper: Achieving success with blended learning. Centra software, 1. Retirado de http://www.leerbeleving.nl/wbts/wbt2014/blendce.pdf

Sousa, A. \& Coutinho, C. (2009). Conteúdos digitais (interactivos) para educação: questões de nomenclatura, reutilização, qualidade e usabilidade.Revista Paidéi@, UNIMES Virtual, 2 (2). Retirado de http://hdl.handle.net/1822/9959

Sweller, J., van Merrienboer, J.J., \& Paas, F.G. (1998). Educational Psychology Review 10 (3), 251-296. doi:10.1023/A:1022193728205 